\title{
Formulation development \& Evaluation of Phospholipids Complex of Euphorbia neriifolia Linn Extract
}

\author{
Pranay Sethiya, Dr. S.C. Mahajan, Mrs. Prachi Maheshwari, Anjali Khantal, \\ Harshita Sharma
}

Mahakal Institute of Pharmaceutical Studies, Ujjain, RGPV, Bhopal, M.P., India

\begin{abstract}
Article Info: Received 05 November 2021; Accepted 02 December 2021
DOI: https://doi.org/10.32553/jbpr.v10i6.891

Corresponding author: Pranay Sethiya

Conflict of interest statement: No conflict of interest
\end{abstract}

\begin{abstract}
Phytoconstituents have been utilized as medicines for thousands of years, yet their application is limited owing to major hurdles like deficit lipid solubility, large molecular size and degradation in the gastric environment of gut. To overcome this hurdle, Novel Drug Delivery System (NDDS) proves to be a promising method for formulations containing phytoconstituents. In present work, phyto-phospholipids complex (phytosomes) of Euphorbia neriifolia L. has been prepared to improve the absorption and bioavailability of phytoconstituents. Euphorbia neriifolia L. consists of flavonoids, saponins and polyphenols which possess various medicinal properties. These constituents are hydrophilic in nature and have large molecular size, thus causing poor absorption. Phyto-phospholipids complex of Euphorbia neriifolia has been prepared by taking Phosphatidylcholine (PC), Cholesterol and Euphorbia neriifolia extract in different ratio and the formulation been optimized to achieve maximum entrapment efficiency and smaller molecular size. The prepared phytosomes has been evaluated by Optical Microscopy, Transmission Electron Microscopy, Dynamic Light Scattering and UV/Vis Spectroscopy for physical appearance, entrapment efficiency, particle size, zeta potential and dissolution rate. The result so obtained indicates the improvement in the absorption rate and bioavailability of the phytoconstituents. Thus, Novel Drug Delivery System (NDDS) possess a great potential in overcoming the challenges of plant based formulations.
\end{abstract}

Keywords: Euphorbia neriifolia, Phyto-phospholipids Complex, Novel Drug Delivery System, Phytosomes

\section{Introduction}

\subsection{Herbal Medicines}

From last thousands of years, the traditional knowledge of herb drugs has been spread from the old generation to the new generation. The newer generation across the world studies plants as a future source of drugs because herbal plant medicines have a strong traditional or conceptual base. It is a possible lead to treat different diseases with least adverse effects. Natural products from medicinal plants have been the source of the management of human disease $^{1-2}$.

Plants fulfills the needs of not only human being but also the entire animal kingdom, particularly 
because of the presence of different bioactive compounds. Ethnopharmacology is the culturally diverse study of how individuals get medicines from fungi, plants, animals or remaining different naturally occurring resources. At present, the field mainly has persistent on developing new drugs on the basis of the medicinal plants use by native peoples. The revelation of the indigenous information about remedial plants may hold clues for relieving diseases, has ended up being a good among the most extensively used conflicts for preserving society and an organic decent variety $^{3}$. The conventional utilization of restorative plants by indigenous networks that reflects the social perspectives just as biodynamic components that have the enormous pharmacological potential to fix numerous illnesses ${ }^{4-5}$.

\subsection{Polyphenols}

Plants are blend from a huge scope of natural aggravates that are customarily delegated essential and auxiliary metabolites. Essential metabolites are aggravates that have basic jobs related with photosynthesis, breathing, development, and improvement. These incorporate nucleotides, amino acids, acyl lipids, phytosterols, and natural acids. Different phytochemicals, huge numbers of which gather in shockingly high focuses in certain species, are alluded to as auxiliary metabolites. There are three noteworthy gatherings on their biosynthetic inceptions can be isolated by the plant auxiliary metabolites ${ }^{6-7}$.

(i) flavonoids and unified phenolic and polyphenolic mixes,

(ii) terpenoids

(iii) nitrogen-containing alkaloids and sulfurcontaining mixes.

\subsection{Nanopharmaceuticals}

Nanoformulations have attracted the interest of many researchers for drug delivery applications. These nano-formulations enhance the properties of conventional drugs and are specific to the targeted delivery site. Dendrimers, liposomes, polymeric nanoparticles, nanoemulsions and micelles are some of the nanoformulations that are gaining importance in the Pharmaceutical industry for enhanced drug formulation ${ }^{8-12}$.

\subsection{Phyto-phospholipids}

Phyto-phospholipid complexes are formed by interactions between active constituents and the polar head of phospholipids ${ }^{13}$. Interactions between active constituents, and phospholipids enable phospholipid complexes to be an integral part in which the phospholipids head group is anchored, but the two long fatty acid chains do not participate in complex formation. The two long fatty acid chains can move and encapsulate the polar part of complexes to form a lipophilic surface. The active ingredient is an integral part of the membrane, being the molecules stabled through hydrogen bonds to the polar head of the phospholipids.

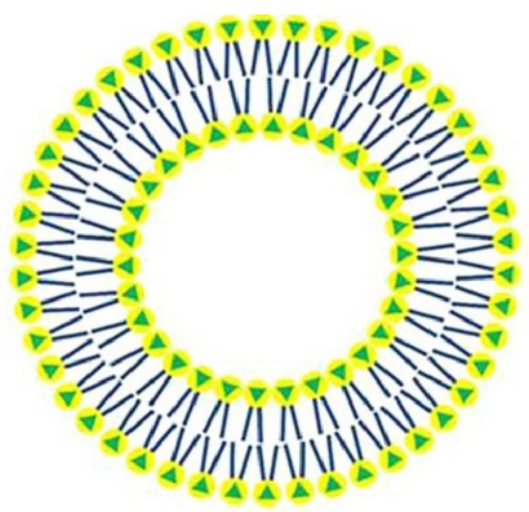

Phyto-Phospholipid Complexes

Figure 1.1: Structure of phyto-phospholipid complexes 
2. Plant Profile (Euphorbia neriifolia L.)

Euphorbia neriifolia Linn (Indian Spurge tree, Hedge Euphorbia commonly known as Snuhi) belong to the family Euphorbiaceae, is one of the different species of Euphorbia genus plants, with wide range of local medicinal uses throughout the areas in which it is grown. This is one of the herbs extensively used in the Indian system of medicine. It is used as analgesic, hepatoprotective, immunostimulant, antiinflammatory, mild CNS depressant, wound healing, radioprotective agent. A significant percentage is succulent, but they are mostly originating from Africa and Madagascar ${ }^{8}$.

\subsection{Scientific Classification}

- Family- Euphorbiaceae

- Kingdom: Plantae

- Subkingdom: Tracheobionta (Vascular plants)
- Superdivision: Spermatophyta (Seed plants)

- Division: Magnoliophyta (Flowering plants)

- Subfamily: Euphorbioideae

- Tribe: Euphorbieae

- Class: Magnoliopsida (Dicotyledons)

- Subclass: Rosidae

- Order: Malpighiales

- Genus: Euphorbia L.

- Species: Spurges (Pencil Cactus)

2.2 Traditional Uses of Euphorbia neriifolia

The traditional uses of E. neriifolia Linn as per Ayurveda are - to improve digestion strength (deepana); induces severe purgation (rechana); useful in treating disorders of vita-dosha imbalance such as neuralgia, paralysis, constipation, bloating, etc; unctuous oily (snigdha); light to digest (leghu); etc ${ }^{14}$

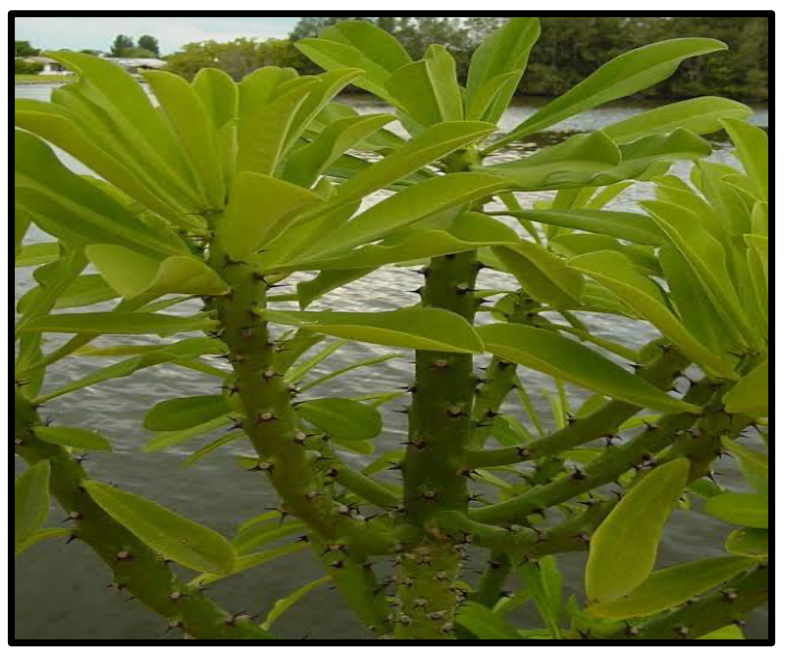

Fig. 2.1 Plant of Euphorbia neriifolia $L$.

\section{Methodology}

\subsection{Collection of Plant material}

Leaves of Euphorbia neriifolia Linn was collected from Ashoka garden Bhopal (M.P), India in month of February, 2021.

\subsection{Identification of Plant material}

The plant has been identified and authenticated by botanist at Department of Botany, Shaheed Bhagat Singh Govt. College, Jaora (M.P.)

\subsection{Extraction procedure}

Following procedure was adopted for the preparation of extract from the shade dried and powdered herbs ${ }^{15-16}$ :

\subsubsection{Defatting of Plant Material}

38.5 gram of leaves of Euphorbia neriifolia Linn were shade dried at room temperature. The shade dried plant material was coarsely powdered and subjected to extraction with petroleum ether using maceration method. The 
extraction was continued till the defatting of the material had taken place.

\subsubsection{Extraction by maceration process}

Defatted Euphorbia neriifolia Linn dried plant material were exhaustively extracted with hydroalcoholic solvent (Ethanol: Water: 70:30). The extract was evaporated above their boiling points. Finally the percentage yields were calculated of the dried extracts.

\subsubsection{Determination of Percentage yield}

The percentage yield of yield of each extract was calculated by using formula:

$\%$ Yield $=\frac{\text { Weight of Extract }}{\text { Weight of Powdered Drug Taken }} \times 100$
The crude extracts so obtained after the maceration process were further concentrated on water bath till the evaporation of solvents to obtain the actual yield of extraction. The percentage yield calculation of extract is a very important concept in phytochemical extraction. To evaluate the standard extraction efficiency for a particular plant, different parts of same plant or different solvents shall be used. The yield of extracts obtained from sample using hydroalcoholic solvent is depicted in the table 3.1 .

Table No. 3.1: Result of percentage yield of extract of Euphorbia neriifolia Linn

\begin{tabular}{|l|l|l|}
\hline S. No. & Solvents & Percentage Yield (\%) \\
\hline 1. & Petroleum ether & 3.12 \\
\hline 2. & Hydroalcoholic & 4.56 \\
\hline
\end{tabular}

\subsection{Qualitative phytochemical tests}

The extracts were subjected to various qualitative tests to detect the presence of plant constituents ${ }^{17-19}$.

Table No. 3.2: Result of phytochemical screening of Euphorbia neriifolia Linn extract

\begin{tabular}{|c|c|c|}
\hline S. No. & Constituents & Hydroalcoholic Extract \\
\hline 1. & $\begin{array}{l}\text { Carbohydrate } \\
\text { Molisch's test: } \\
\text { Benedict's test: } \\
\text { Fehling's Test: }\end{array}$ & $\begin{array}{l}\text {-ve } \\
\text {-ve } \\
\text {-ve }\end{array}$ \\
\hline 2. & $\begin{array}{c}\text { Alkaloids } \\
\text { Dragendorff's Test: } \\
\text { Wagner's test: } \\
\text { Mayer's Test: } \\
\text { Hager's Test: }\end{array}$ & $\begin{array}{l}\text {-ve } \\
\text {-ve } \\
\text {-ve } \\
\text {-ve }\end{array}$ \\
\hline 3. & $\begin{array}{l}\text { Glycosides } \\
\text { Legal's test: }\end{array}$ & -ve \\
\hline 4. & $\begin{array}{c}\text { Saponins } \\
\text { Froth test: } \\
\text { Foam Test: } \\
\end{array}$ & $\begin{array}{l}+\mathrm{ve} \\
+\mathrm{ve}\end{array}$ \\
\hline 5. & $\begin{array}{c}\text { Flavonoids } \\
\text { Alkaline Reagent Test: } \\
\text { Lead acetate Test: }\end{array}$ & $\begin{array}{l}+\mathrm{ve} \\
+\mathrm{ve}\end{array}$ \\
\hline 6. & $\begin{array}{c}\text { Proteins } \\
\text { Xanthoprotein test: }\end{array}$ & -ve \\
\hline 7. & $\begin{array}{c}\text { Phenol } \\
\text { Ferric Chloride Test: }\end{array}$ & $+\mathrm{ve}$ \\
\hline 8. & $\begin{array}{c}\text { Diterpenes } \\
\text { Copper acetate Test: }\end{array}$ & -ve \\
\hline 9. & $\begin{array}{c}\text { Tannins } \\
\text { Gelatin Test: }\end{array}$ & -ve \\
\hline
\end{tabular}


From the results obtained it is clear that the Euphorbia neriifolia Linn plant shows the presence of saponins, flavonoids and phenol.

3.4 Quantitative estimation of phytoconstituents

\subsubsection{Total phenolic content estimation}

Principle: The total phenolic content of the extract was determined by the modified FolinCiocalteu method ${ }^{20}$.

Preparation of Standard: $10 \mathrm{mg}$ Gallic acid was dissolved in $10 \mathrm{ml}$ methanol, various aliquots of $10-50 \mu \mathrm{g} / \mathrm{ml}$ was prepared in methanol
Preparation of Extract: $10 \mathrm{mg}$ of dried extract was dissolved in $10 \mathrm{ml}$ methanol and filter. Two $\mathrm{ml}(1 \mathrm{mg} / \mathrm{ml})$ of this extract was used for the estimation of phenol.

Procedure: $2 \mathrm{ml}$ of methanolic extract and each standard was mixed with $1 \mathrm{ml}$ of Folin-Ciocalteu reagent (previously diluted with GA: distilled water $1: 10 \mathrm{v} / \mathrm{v})$ and $1 \mathrm{ml}(7.5 \mathrm{~g} / \mathrm{l})$ of sodium carbonate. The mixture was vortexed for $15 \mathrm{~s}$ and allowed to stand for $10 \mathrm{~min}$ for colour development. The absorbance was measured at $765 \mathrm{~nm}$ using a spectrophotometer.

Table No. 3.3: Preparation of calibration curve of Gallic acid

\begin{tabular}{|l|l|l|}
\hline S. No. & Concentration $(\boldsymbol{\mu g} / \mathbf{m l})$ & Absorbance \\
\hline 0 & 0 & 0 \\
\hline 1 & 10 & 0.135 \\
\hline 2 & 20 & 0.247 \\
\hline 3 & 30 & 0.364 \\
\hline 4 & 40 & 0.474 \\
\hline 5 & 50 & 0.581 \\
\hline
\end{tabular}

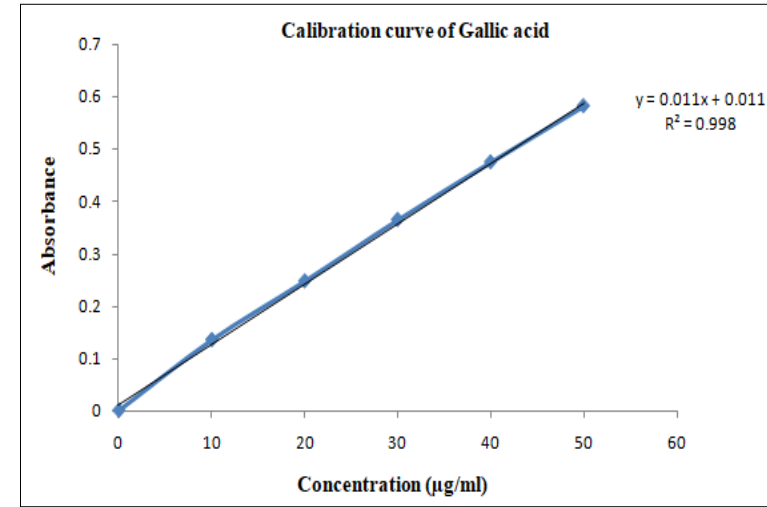

Figure 3.1: Graph of calibration curve of GA

\subsubsection{Total flavonoid content estimation}

Principle: Determination of total flavonoids content was based on aluminium chloride method.

Preparation of standard: $10 \mathrm{mg}$ quercetin was dissolved in $10 \mathrm{ml}$ methanol, and various aliquots of $5-25 \mu \mathrm{g} / \mathrm{ml}$ were prepared in methanol.
Preparation of extract: $10 \mathrm{mg}$ of dried extracted dissolve in $10 \mathrm{ml}$ methanol and filter. Three $\mathrm{ml}(1 \mathrm{mg} / \mathrm{ml})$ of this extract was used for the estimation of flavonoid.

Procedure: $1 \mathrm{ml}$ of $2 \% \mathrm{AlCl}_{3}$ methanolic solution was added to $3 \mathrm{ml}$ of extract or standard and allowed to stand for $15 \mathrm{~min}$ at room temperature; absorbance was measured at 420 nm. 
Table No. 3.4: Preparation of calibration curve of Quercetin

\begin{tabular}{|l|l|l|}
\hline S. No. & Concentration $(\boldsymbol{\mu g} / \mathbf{m l})$ & Absorbance \\
\hline 0 & 0 & 0 \\
\hline 1 & 5 & 0.214 \\
\hline 2 & 10 & 0.452 \\
\hline 3 & 15 & 0.711 \\
\hline 4 & 20 & 0.917 \\
\hline 5 & 25 & 1.145 \\
\hline
\end{tabular}

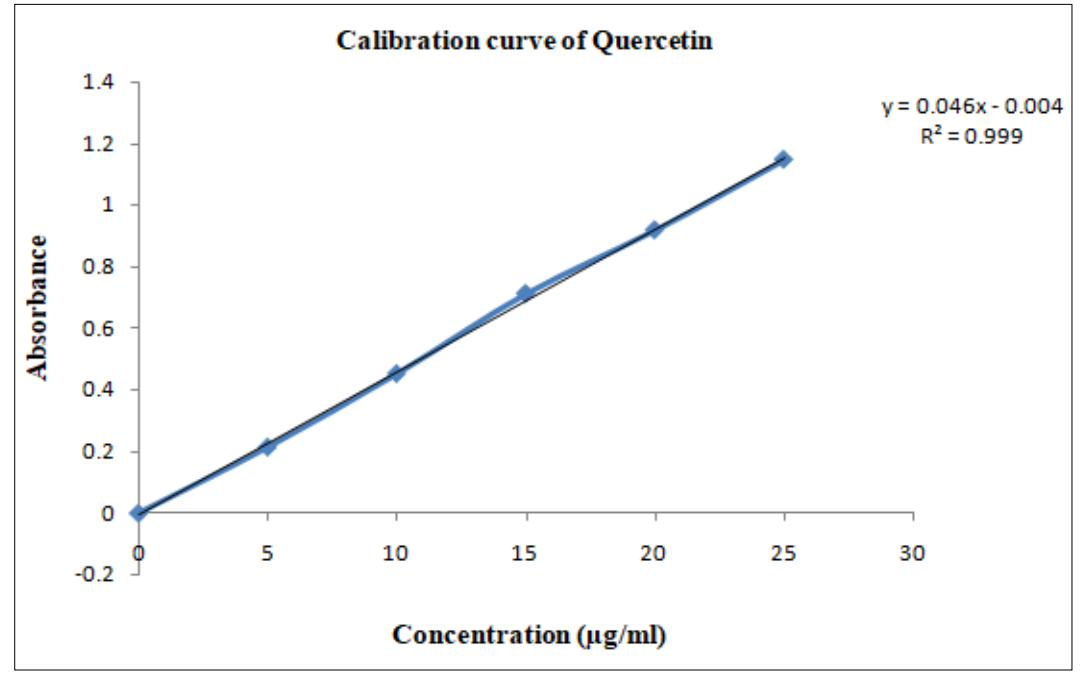

Figure 3.2: Graph of calibration curve of Quercetin

Table No. 3.5: Total phenol and flavonoid content of Hydroalcoholic extract of Euphorbia neriifolia Linn

\begin{tabular}{|l|l|l|}
\hline S. No. & Euphorbia neriifolia Linn extract \\
\hline 1. & Total phenol (GAE) $(\mathrm{mg} / 100 \mathrm{mg})$ & 0.762 \\
\hline 2. & Total flavonoid (QE) $(\mathrm{mg} / 100 \mathrm{mg})$ & 0.924 \\
\hline
\end{tabular}

\subsection{Formulation development of} phospholipids complex

The complex was prepared with phospholipids, Cholesterol and Euphorbia neriifolia Linn extract in the ratio of $1: 1: 1,1: 2: 1,2: 1: 1,2: 3: 1$ respectively ${ }^{21}$. Weighed amount of extract, phospholipids and cholesterol were placed in a $100 \mathrm{ml}$ round-bottom flask and $25 \mathrm{ml}$ of dichloromethane was added as reaction medium. The mixture was refluxed and the reaction temperature of the complex was controlled to $50^{\circ} \mathrm{C}$ for $3 \mathrm{~h}$. The resultant clear mixture was evaporated and $20 \mathrm{ml}$ of $\mathrm{n}$-hexane was added to it with stirring. The precipitate was filtered and dried under vacuum to remove the traces amount of solvents. The dried residues were gathered and placed in desiccators overnight and stored at room temperature in an amber colored glass bottle. 


\begin{tabular}{|c|c|c|c|}
\hline Formulation & $\begin{array}{c}\text { Ratio of Phospholipids } \\
\text { and Cholesterol }\end{array}$ & $\begin{array}{c}\text { Extract Concentration } \\
(\mathbf{\%})\end{array}$ & $\begin{array}{c}\text { Dichloromethane } \\
\text { Concentration }\end{array}$ \\
\hline \multicolumn{4}{|c|}{ Optimization of Phospholipids and Cholesterol } \\
\hline F1 & $1: 1$ & 1 & 25 \\
\hline F2 & $1: 2$ & 1 & 25 \\
\hline F3 & $\mathbf{2 : 1}$ & $\mathbf{1}$ & 25 \\
\hline F4 & $2: 3$ & 1 & 25 \\
\hline \multicolumn{5}{|c|}{ Optimization of Drug Concentration } \\
\hline F5 & $2: 1$ & 0.5 & $\mathbf{2 5}$ \\
\hline F6 & $\mathbf{2 : 1}$ & 1.0 & 25 \\
\hline F7 & $2: 1$ & 2.0 & 10 \\
\hline F8 & $2: 1$ & 1.0 & $\mathbf{2 5}$ \\
\hline & Optimization of solvent concentration & 50 \\
\hline F9 & $2: 1$ & $\mathbf{1 . 0}$ & 75 \\
\hline F10 & $\mathbf{2 : 1}$ & 1.0 & 25 \\
\hline F11 & $2: 1$ & 1.0 & \\
\hline F12 & $2: 1$ & & \\
\hline
\end{tabular}

\subsection{Evaluation of Prepared phospholipids}

\section{Complex}

The prepared phytosomes has been evaluated by Optical Microscopy, Transmission Electron Microscopy, Dynamic Light Scattering and UV/Vis Spectroscopy for physical appearance, entrapment efficiency, particle size, zeta potential and dissolution rate.

3.6.1 Microscopic observation of prepared phospholipids complex

An optical microscope with a camera attachment was used to observe the shape of the optimized phospholipids complex formulation.

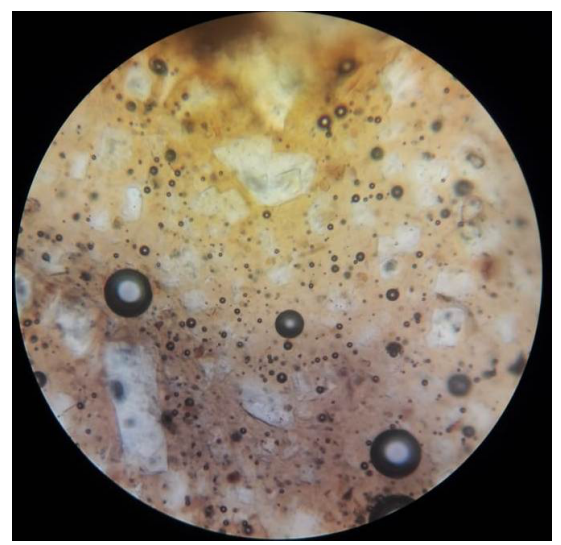

Figure 3.3: Microscopic observation of optimized batch F10

\subsubsection{Drug-Excipient compatibility study}


The spectrum of extract and phospholipids complex was authenticated by FTIR spectroscopy. The presences of characteristic peaks associated with specific structural characteristics of the drug molecule were noted. Various peaks of the drug are shown in Figure 3.4 and the wave numbers are listed in Table 7.6.

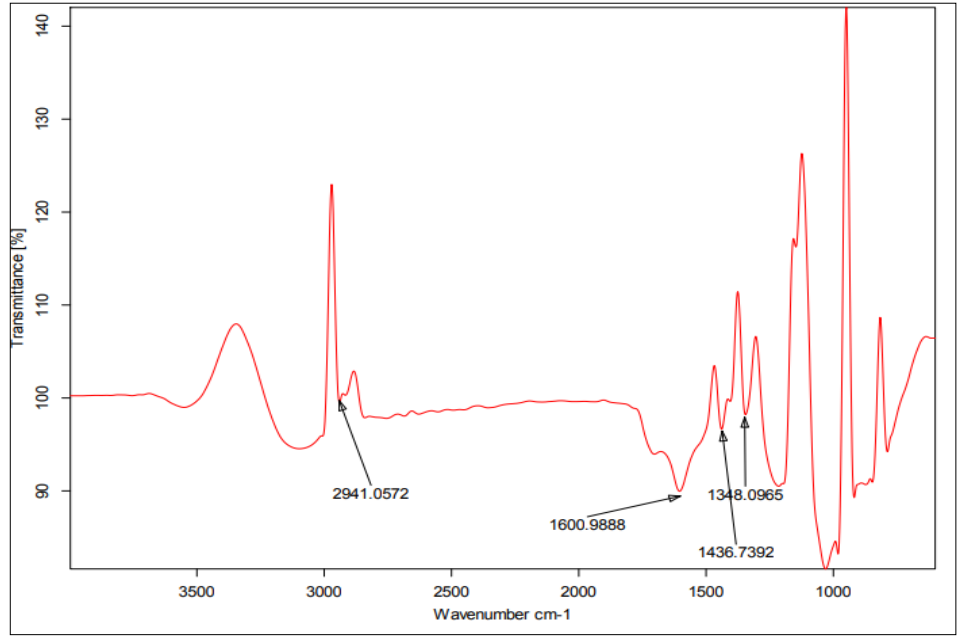

Figure 3.4: FT-IR spectra of hydroalcoholic extract

Table 3.7: Interpretation of FT-IR spectrum

\begin{tabular}{|l|l|l|l|}
\hline \multirow{2}{*}{ S. No. } & \multirow{2}{*}{ Functional group } & \multicolumn{2}{|l|}{ Peak wave number $\left(\mathbf{c m}^{-1}\right)$} \\
\cline { 3 - 4 } & & Experimental & Theoretical \\
\hline 1. & C-C str. and C=O str. & 1600.9880 & $1550-1650$ \\
\hline 2. & O-H str. & 2941.0572 & $3200-2800$ \\
\hline 3. & C $=$ C aromatic str. & 1436.7392 & $1400-1450$ \\
\hline
\end{tabular}

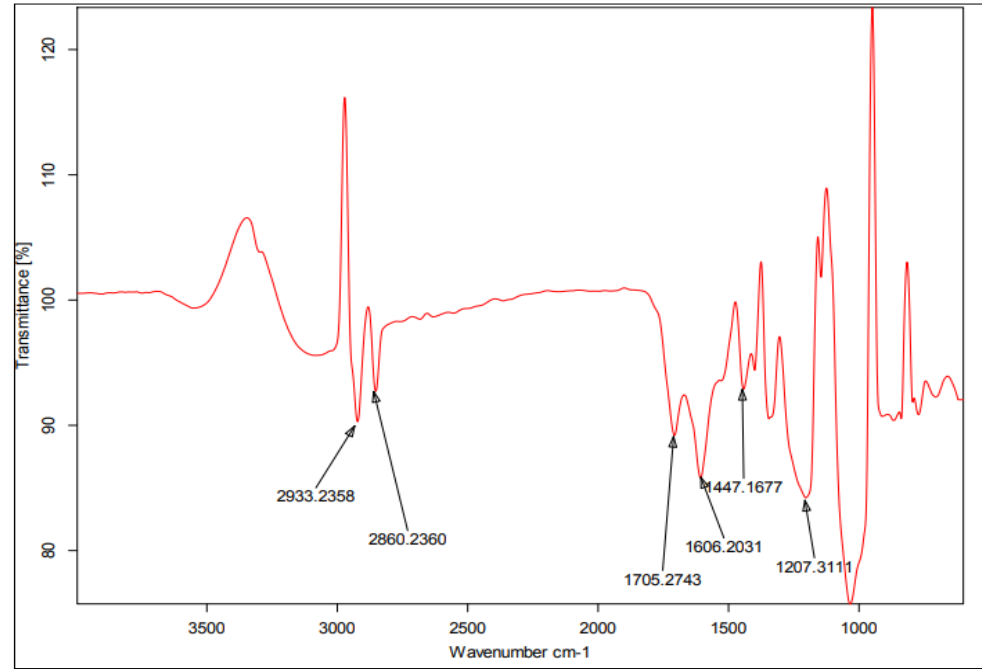

Figure 3.5: FT-IR spectra of prepared phospholipids complex formulation

The appearance or disappearance of peaks and/or the shift of their positions are often indications of interactions such as hydrogen bonding. The IR spectra of extract, Fig. 7.6 7.7, 
shows stretching vibrations at $1600.9880 \mathrm{~cm}^{-1}$ attributed predominantly to the overlapping stretching vibrations of alkenes $(\mathrm{C}=\mathrm{C})$ and carbonyl $(\mathrm{C}=\mathrm{O})$ character. Infrared of extract show stretching vibration at $2941.0572 \mathrm{~cm}^{-1}$ due to $\mathrm{O}-\mathrm{H}$ groups, $\mathrm{C}=\mathrm{C}$ aromatic stretching vibration at $1436.7392 \mathrm{~cm}^{-1}$. When the data obtained from FTIR spectra is compared with the spectra studied it was observed that there are similar peaks for functional groups in phospholipids complex.

From the FTIR data of the physical mixture it is clear that functionalities of drug have remained unchanged including intensities of the peak. This suggests that during the process drug, Phospholipids and Cholesterol has not reacted with the drug to give rise to reactant products. So there is no interaction between them which is in favor to proceed for formulation of phospholipids complex as drug delivery system.

\subsubsection{Entrapment efficiency and particle size analysis}

Entrapment efficiency is an important parameter for characterizing phospholipids complex. In order to attain optimal encapsulation efficiency, several factors were varied, including the concentration of the lipid, concentration of drug and concentration of alcohol. The entrapment efficiency of all the prepared formulations is shown in Table 3.8. The entrapment efficiency of the phospholipids complex was found in the range of $45.65 \pm 0.25$ to $71.12 \pm 0.42 \%$. Particle size of all formulations found within range $312.25 \pm 0.58-465.25 \pm 0.32 \mathrm{~nm}$. Concentration of lipid has shows significant impact on size of phospholipids complex. Formulation F10 was found best one which is further evaluated for drug release study, transmission electron microscopy (TEM), and stability studies.

Table 3.8: Particle size and entrapment efficiency of drug loaded phospholipids complex

\begin{tabular}{|c|c|c|}
\hline Formulation Code & $\begin{array}{c}\text { Particle size } \\
\text { (nm) }\end{array}$ & $\begin{array}{c}\text { Entrapment Efficiency } \\
\text { (\%) }\end{array}$ \\
\hline F1 & $465.25 \pm 0.32$ & $45.65 \pm 0.25$ \\
\hline F2 & $425.58 \pm 0.45$ & $48.85 \pm 0.45$ \\
\hline F3 & $\mathbf{2 9 8 . 4 5} \pm \mathbf{0 . 2 5}$ & $\mathbf{6 5 . 3 2} \pm \mathbf{0 . 2 2}$ \\
\hline F4 & $312.23 \pm 0.63$ & $59.98 \pm 0.14$ \\
\hline F5 & $305.65 \pm 0.54$ & $57.74 \pm 0.32$ \\
\hline F6 & $\mathbf{2 4 8 . 8 5} \pm \mathbf{0 . 4 7}$ & $\mathbf{6 8 . 6 5} \pm \mathbf{0 . 6 5}$ \\
\hline F7 & $312.25 \pm 0.58$ & $59.98 \pm 0.54$ \\
\hline F8 & $322.45 \pm 0.65$ & $52.23 \pm 0.14$ \\
\hline F9 & $315.65 \pm 0.21$ & $59.98 \pm 0.55$ \\
\hline F11 & $\mathbf{2 4 5 . 6 5} \pm \mathbf{0 . 3 4}$ & $\mathbf{7 1 . 1 2} \pm \mathbf{0 . 4 2}$ \\
\hline F12 & $298.85 \pm 0.58$ & $64.65 \pm 0.28$ \\
\hline & $285.65 \pm 0.25$ & $63.32 \pm 0.35$ \\
\hline
\end{tabular}

\subsubsection{Transmission Electron Microscopy (TEM)}

TEM characterization revealed that the phospholipids complex is spherical in shape (Figure 3.6). However, some variation in size distribution was observed in the TEM image, which might be attributed to an uncontrolled charge neutralization process involved between oppositely charged chains occurring during the formation of phospholipids complex. 


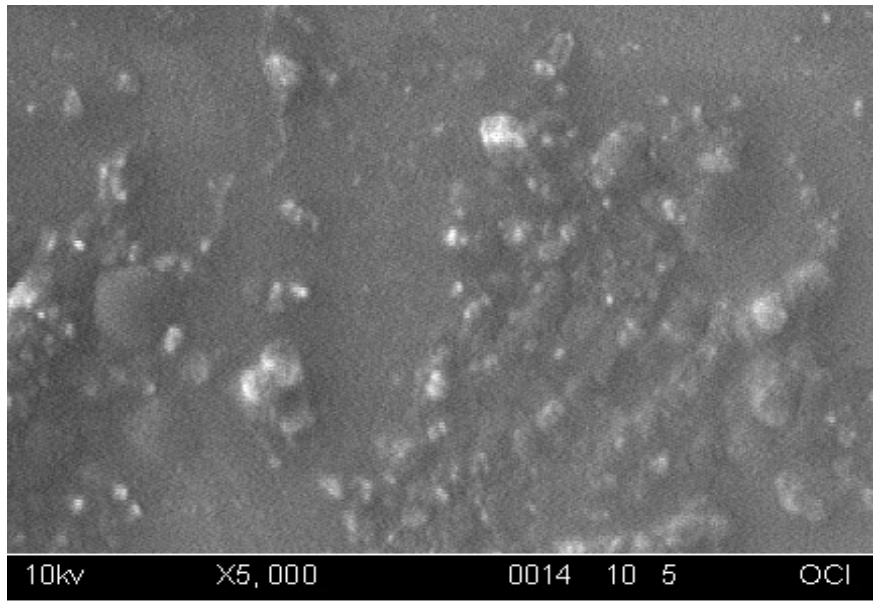

Figure 3.6: TEM image of phospholipids complex

Table 3.9: In-vitro drug release data for optimized formulation F10

\begin{tabular}{|c|c|c|c|c|c|c|}
\hline Time (h) & $\begin{array}{c}\text { Square } \\
\text { Root of } \\
\text { Time(h) }\end{array}$ & $\begin{array}{c}\text { Log } \\
\text { Time }\end{array}$ & $\begin{array}{c}\text { Cumulati } \\
\text { ve*\% } \\
\text { Drug } \\
\text { Release }\end{array}$ & $\begin{array}{c}\text { Log } \\
\text { Cumulative } \\
\text { \% Drug } \\
\text { Release }\end{array}$ & $\begin{array}{c}\text { Cumulative } \\
\text { \% Drug } \\
\text { Remaining }\end{array}$ & $\begin{array}{c}\text { Log } \\
\text { Cumulative } \\
\text { \% Drug } \\
\text { Remaining }\end{array}$ \\
\hline 0.5 & 0.707 & -0.301 & 18.85 & 1.275 & 81.15 & 1.909 \\
\hline 1 & 1 & 0 & 32.25 & 1.509 & 67.75 & 1.831 \\
\hline 2 & 1.414 & 0.301 & 43.32 & 1.637 & 56.68 & 1.753 \\
\hline 4 & 2 & 0.602 & 58.85 & 1.770 & 41.15 & 1.614 \\
\hline 6 & 2.449 & 0.778 & 71.12 & 1.852 & 28.88 & 1.461 \\
\hline 8 & 2.828 & 0.903 & 86.65 & 1.938 & 13.35 & 1.125 \\
\hline 12 & 3.464 & 1.079 & 99.45 & 1.998 & 0.55 & -0.260 \\
\hline
\end{tabular}

3.6.5 In vitro drug release study of prepared phospholipids complex formulation

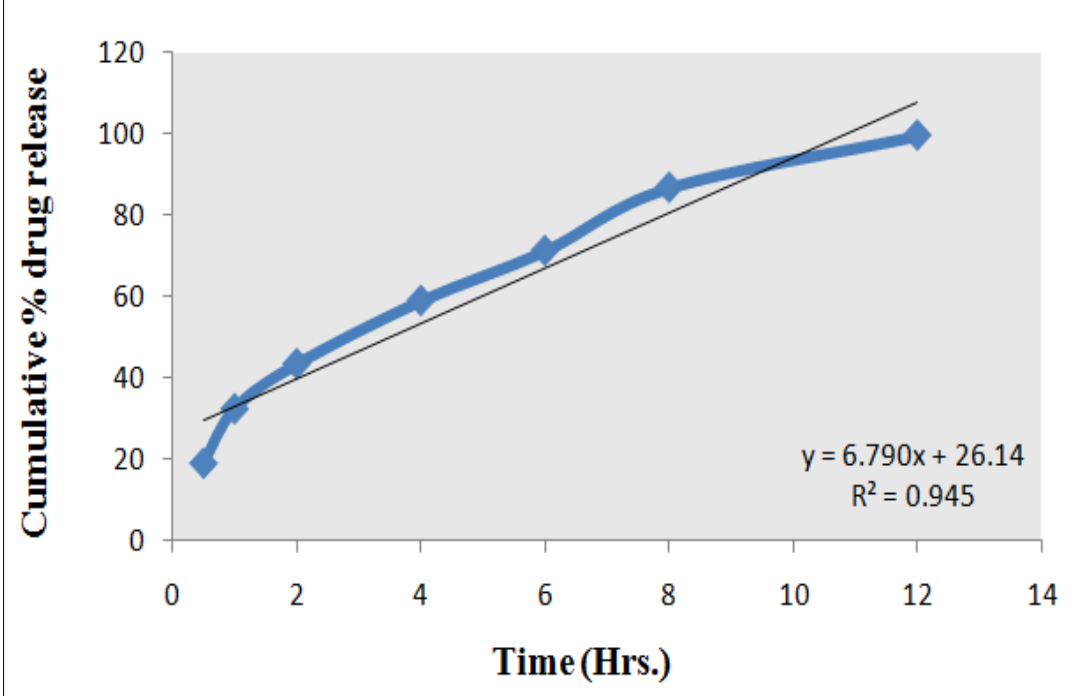

Figure 3.7: Cumulative \% drug released Vs Time

(Zero Order Kinetics) 


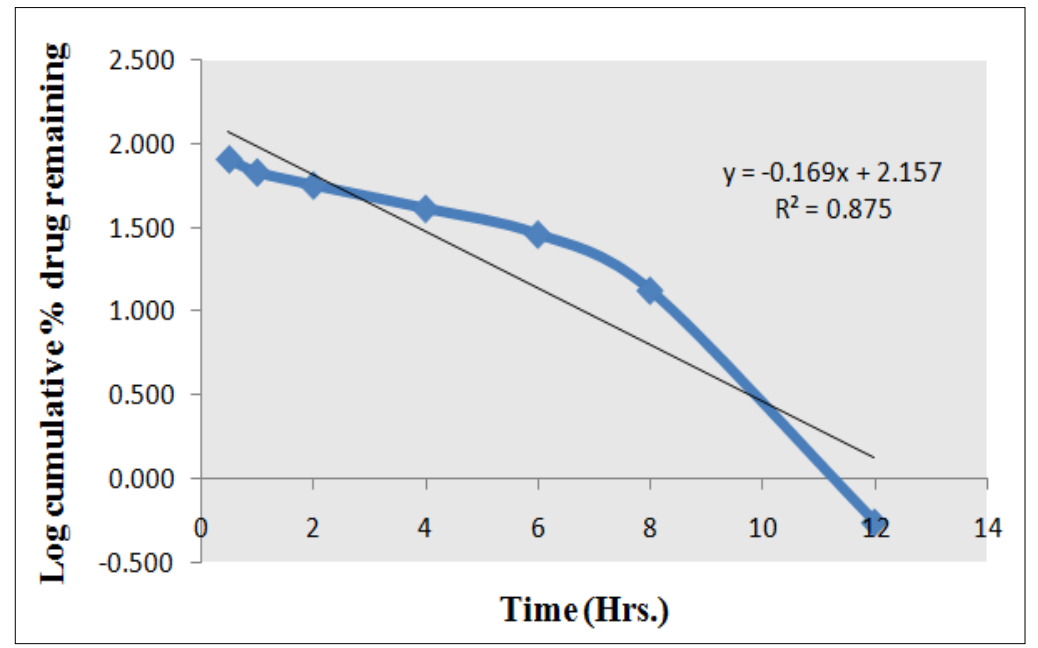

(First Order Kinetics)

Figure 3.8: Log cumulative \% drug remaining Vs Time

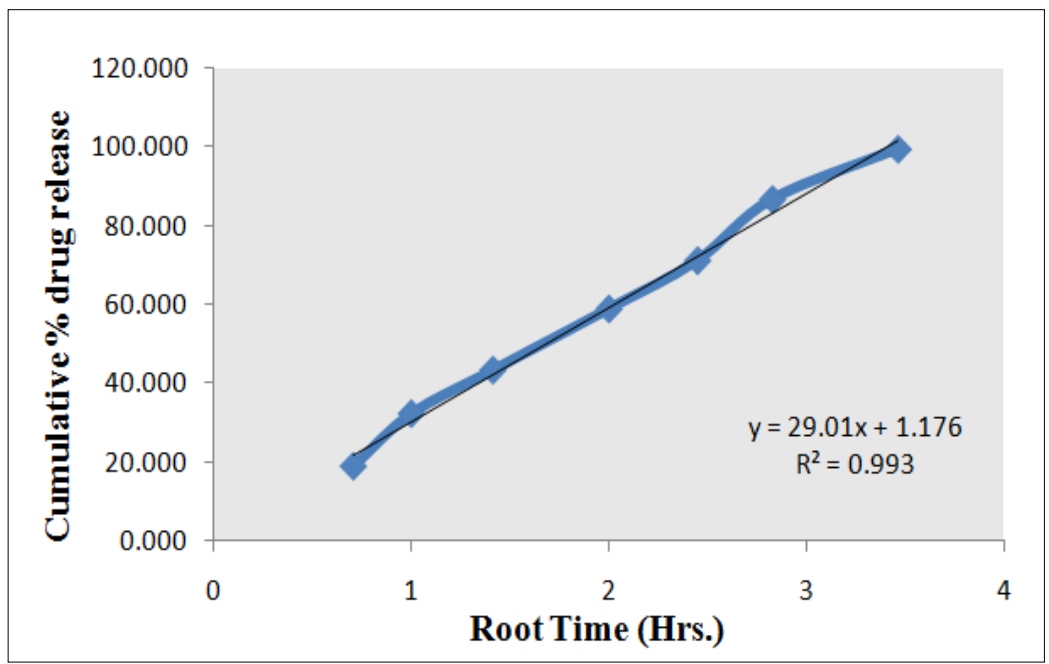

Figure 3.9: Cumulative \% drug release Vs Root time (Higuchi Release Kinetics)

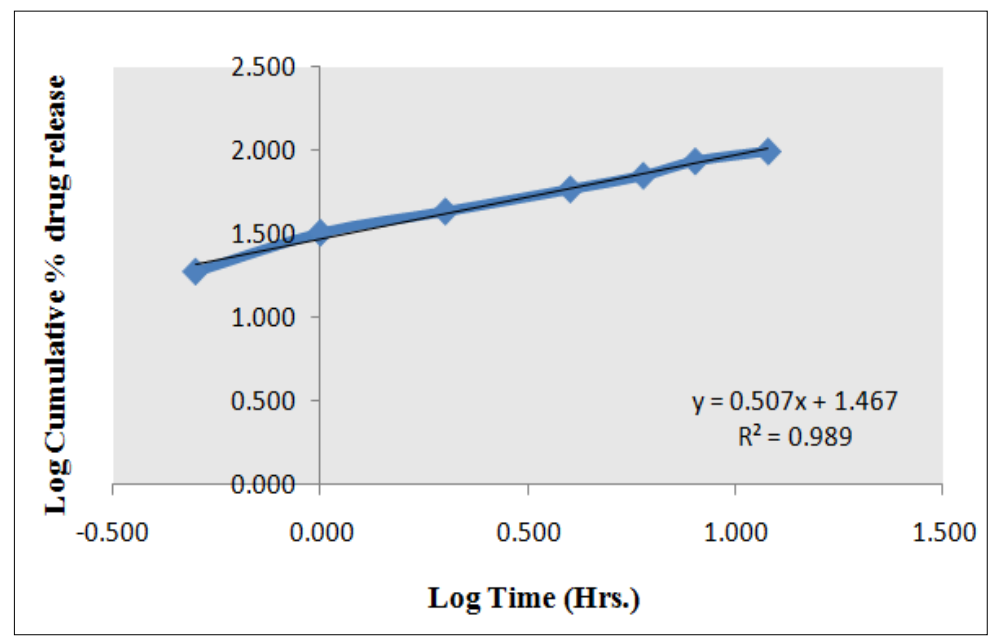

Figure 3.10: Log Cumulative \% drug release Vs Log time (Korsmeyer Peppas Model) 
Table 3.10: Regression analysis data of optimized formulation F10

\begin{tabular}{|l|l|l|l|l|}
\hline \multirow{2}{*}{ Batch } & Zero Order & First Order & Higuchi & Korsmeyer Peppas \\
\cline { 2 - 5 } & $\mathbf{R}^{\mathbf{2}}$ & $\mathbf{R}^{\mathbf{2}}$ & $\mathbf{R}^{\mathbf{2}}$ & $\mathbf{R}^{\mathbf{2}}$ \\
\hline F10 & 0.945 & 0.875 & 0.993 & 0.989 \\
\hline
\end{tabular}

When the regression coefficient values of were compared, it was observed that ' $\mathrm{r}$ ', values of Higuchi was maximum i.e. 0.993 hence indicating drug release from formulations was found to follow Higuchi release kinetics.

\subsection{Stability studies}

Results of stability studies clearly indicates that optimized batches of phospholipids complex were stable over the chosen temperature and humidity conditions up to 3 months as were found no significant variation in physical appearance and $\%$ drug content.

\section{Discussion and Conclusion}

In the present research we have prepared the phospholipids complex of Euphorbia neriifolia $L$. The percentage yield of Euphorbia neriifolia Linn exhibited higher yield in hydroalcoholic extract $4.56 \%$ respectively. Petroleum ether exhibited comparable yield $3.12 \%$ due to non polarity of Petroleum ether. The hydroalcoholic extracts possess almost all the phytochemicals that were tested. From the results obtained it is clear that the Euphorbia neriifolia Linn plant shows the presence of saponins, flavonoids and phenol. The total phenolic and flavonoid content in hydroalcoholic extract of Euphorbia neriifolia Linn was found $0.762 \mathrm{mg} / 100 \mathrm{mg}$ and $0.924 \mathrm{mg} / 100 \mathrm{mg}$ respectively. From the FTIR data of the physical mixture it is clear that functionalities of drug have remained unchanged including intensities of the peak. This suggests that during the process, Phospholipids and Cholesterol has not reacted with the drug to give rise to reactant products. So there is no interaction between them which is in favor to proceed for formulation of phospholipids complex as drug delivery system. Entrapment efficiency is an important parameter for characterizing phospholipids complex. In order to attain optimal encapsulation efficiency, several factors were varied, including the concentration of the lipid, concentration of drug and concentration of alcohol. The entrapment efficiency of all the prepared formulations were checked. The entrapment efficiency of the phospholipids complex was found in the range of $45.65 \pm 0.25$ to $71.12 \pm 0.42 \%$. Particle size of all formulations found within range $312.25 \pm 0.58-465.25 \pm 0.32 \mathrm{~nm}$. Concentration of lipid has shows significant impact on size of phospholipids complex. Formulation F10 was found best one which is further evaluated for drug release study, transmission electron microscopy (TEM), and stability studies. When the regression coefficient values of were compared, it was observed that ' $\mathrm{r}$ ' 'values of Higuchi was maximum i.e. 0.993 hence indicating drug release from formulations was found to follow Higuchi release kinetics. Results of stability studies clearly indicates that optimized batches of phospholipids complex were stable over the chosen temperature and humidity conditions up to 3 months as were found no significant variation in physical appearance and \% drug content. It can be concluded that the phospholipids complex containing Euphorbia neriifolia can provide a convenient and safe alternative to dosage form.

\section{References}

1. Cox PA and Balick MJ. 1994. The ethnobotanical approach to drug discovery. Sci Am., 270: 82-87.

2. Etkin NL. 1993. Anthropological methods in Ethnopharmacology. J Ethnopharmacology 38: 93-104.

3. Farnsworth NR. 1988. Screening plants for new medicines. In: Wilson, E.O. (Ed.), Biodiversity. National Academic Press, Washington, DC. p. 83-97. 
4. Cox PA and Balick MJ. 1994. The ethnobotanical approach to drug discovery. Sci Am., 270: 82-87.

5. Etkin NL. 1993. Anthropological methods in Ethnopharmacology. J Ethnopharmacol. 38: 93-104.

6. Croteau, R., Kutchan, T.M. and Lewis, N.G. (2000) Natural products (secondary metabolites. In B.B. Buchannan, W. Gruissem and R.L. Jones (eds), Biochemistry and Molecular Biology of Plant. American Society of Plant Physiologists, Rockville M.D., pp. 12501318.

7. Dewick P.M. (2002). Medicinal Natural Products: A Biosynthetic Approach, 2nd edition, John Wiley and Sons, Chichester.

8. Devi V.K., Jain N., Valli K.S.. Importance of novel drug delivery systems in herbal medicines. Pharmacognosy Rev 2010; 4(7):27-31.

9. Ansari SH, Islam F, Sameem M. Influence of nanotechnology on herbal drugs: A review. J Adv Pharm Technology Res 2012; 3(3):142-6.

10. Shaikh MS, Derle ND, Bhamber R. Permeability enhancement techniques for poorly permeable drugs: A review. J Appl Pharm Sci 2012; 02(06):34-9.

11. Ekladious I., Colson Y.L., Grinstaff M.W., Polymer-drug conjugate therapeutics: advances, insights and prospects. Nat Rev Drug Discovery 2019, 18(4): 273-294.

12. J Khan, A Alexander, S Saraf, S Saraf. Recent advances and future prospects of phyto-phospholipid complexation technique for improving pharmacokinetic profile of plant actives. J Control Release, 168 (1) (2013), pp. 50-60

13. Shaikh A Ahmed, Sayyed Nazim, Shaikh Siraj, Patel M Saddik, Chavda Ab Wahid (2011) Euphorbia neriifolia Linn: A
Phytopharmacological Review IRJP 2(5): 41-48.

14. Pracheta J, Sharma V, Paliwal R, Sharma S (2011) Preliminary phytochemical screening and in-vitro antioxidant potential of hydroethanolic extract of Euphorbia neriifolia L. Int J Pharm Tech Res 3(1): 124132.

15. Mukherjee PK. Quality Control of Herbal Drugs, $2^{\text {nd }}$ Edition, Business Horizons, 2007; 2-14.

16. Kokate CK. Ed. Practical Pharmacognosy, $4^{\text {th }}$ Edn., Vallabh Prakashan: 1994; 112:120.

17. Roopashree TS, Dang R, Rani SRH, Narendra C. Antibacterial activity of antipsoriatic herbs: Cassia tora, Momordica charantia and Calendula officinalis. International Journal of Applied Research in Natural Products 2008; 1(3): 20-28.

18. Obasi NL, Egbuonu ACC, Ukoha PO, Ejikeme PM. Comparative phytochemical and antimicrobial screening of some solvent extracts of Samanea saman pods. African journal of pure and applied chemistry 2010; 4(9): 206-212.

19. Audu SA, Mohammed I, Kaita HA. Phytochemical screening of the leaves of Lophira lanceolata (Ochanaceae). Life Science Journal 2007; 4(4): 75-79.

20. Olufunmiso, Olajuyigbe, O. and Afolayan, Anthony, J. (2011). phenolic Content and antioxidant property of the bark extract of Ziziphus mucronata wild. Subsp. Mucronata wild, BMC, Complementary and alternative medicine. 11: 130.

21. Ashwini S Dhase, Shweta S Saboo, Preparation and Evaluation of Phytosomes Containing Methanolic Extract of Leaves of Aegle Marmelos (Bael) International Journal of PharmTech Research IJPRIF, 2015; Vol.8, No.6, 231-240. 